\title{
Estrutura de Capital e Peculiaridades Regionais nas Cooperativas Agropecuárias do Paraná - Brasil ${ }^{1}$
}

\author{
Jessé Aquino Rodrigues², Gerson José Lauermann², \\ Vilmar Rodrigues Moreira ${ }^{4}$, Alex Antônio Ferraresii ${ }^{5}$ e Alceu Souza ${ }^{6}$
}

Resumo: Este estudo tem por objetivo caracterizar a estrutura de capital das cooperativas agropecuárias paranaenses e suas peculiaridades regionais. Foram analisados os contextos históricos regionais e as formas de capitalização vis-à-vis os processos de colonização de imigrantes europeus e de outros estados brasileiros e os projetos regionais de desenvolvimento. Para tal, foi utilizada uma amostra intencional das 43 cooperativas paranaenses que, juntas, representam 99,5\% do faturamento total do ramo. As peculiaridades regionais foram analisadas por meio de Análise de Variância (ANOVA) e mapeamento perceptual. Conclui-se que é possível identificar agrupamentos de cooperativas segundo estratégias de capitalização e características regionais. Dentre as regiões analisadas, as cooperativas da região oeste do estado do Paraná, por terem maior nível de industrialização, possuem maior necessidade de capital de giro, enquanto a maioria das cooperativas do centro-sul do estado apresenta tesouraria positiva. Uma limitação do estudo é que, sem entender qual modelo poderia ser eleito o melhor para o setor, a questão da estrutura ótima de capital ainda permanece aberta para as cooperativas agropecuárias.

Palavras-chaves: estrutura de capital, cooperativas agropecuárias, capitalização.

Abstract: This study aims to characterize the capital structure of Paraná's agribusiness cooperatives and their regional peculiarities. We analyzed regional historical contexts and the forms of capitalization vis-à-vis the colonization processes of European and other Brazilian immigrants and the regional development projects. For this purpose, an intentional sample of the 43 cooperatives of Paraná state was used, representing 99.5\% of the total revenue of all agribusiness cooperatives

1. Data de submissão: 25 de fevereiro de 2016. Data de aceite: 11 de setembro de 2017.

2. Sistema Ocepar-Sescoop/PR, Curitiba-PR, Brasil. E-mail: jesse.rodrigues@sistemaocepar.coop.br

3. Sistema Ocergs - Sescoop/RS, Porto Alegre-RS, Brasil. E-mail: gerson.lauermann@ sistemaocepar.coop.br

4. Pontifícia Universidade Católica do Paraná - PUCPR, Curitiba-PR, Brasil. E-mail: vilmar.moreira@ pucpr.br

5. Pontifícia Universidade Católica do Paraná - PUCPR, Curitiba-PR, Brasil. E-mail: alex.ferraresi@ pucpr.br

6. Pontifícia Universidade Católica do Paraná - PUCPR, Curitiba-PR, Brasil. E-mail: alceu.souza@ pucpr.br 
of the state. It was used ANOVA and perceptual mapping to analyze the cooperatives and to identify regional peculiarities. It is concluded that it is possible to group cooperatives according to capitalization strategies and regional characteristics. Among regions analyzed, cooperatives in the western region of Paraná, due to their higher level of industrialization, have greater working capital requirement, and the cooperatives in the center-south mostly have a positive cash position. One limitation of the study is that, without understanding which model could be elected the best for the sector, the question of optimal capital structure remains open for agribusiness cooperatives.

Key-words: capital structure, agribusiness cooperatives, capitalization.

Classificação JEL: G32, Q13.

DOI: http://dx.doi.org/10.1590/1234-56781806-94790560202

\section{Introdução}

No Brasil, o cooperativismo é dividido em 13 ramos de atuação, e um dos mais importantes e representativos é o agropecuário. A relevância das cooperativas agropecuárias é evidenciada por Iliopoulos, Cook e Chaddad (2016). Os autores apresentam uma coletânea de estudos que concluem que não existe país com agricultura avançada onde as cooperativas não apresentem um papel determinante em todos os elos da cadeia produtiva de alimentos.

No Paraná, estado com grande tradição e vocação para atividades rurais (MACHINSKI et al., 2016), segundo dados da Organização das Cooperativas do Estado do Paraná (Ocepar), possui 77 cooperativas agropecuárias filiadas a ela. Em 2014, essas cooperativas faturaram mais de $\mathrm{R} \$ 42$ bilhões, congregaram cerca de 140 mil cooperados e o volume de exportações foi de cerca de R\$ 6 bilhões. Essas cooperativas representam atualmente $55 \%$ da economia agrícola do Paraná e participam ativamente dos processos de produção, beneficiamento, armazenagem e industrialização de grande parte dos produtos agropecuários produzidos no estado (OCEPAR, 2014; MACHINSKI et al., 2016). Embora atualmente as cooperativas agropecuárias tenham representatividade importante na economia do estado, em um passado recente enfrentaram dificuldades advindas de crises econômicas, problemas climáticos, variação cambial e de custos de produção. Essas adversidades estão sendo superadas por gestões mais profissionalizantes e atitudes de sustentabilidade empresarial.
A estratégia de crescimento das cooperativas direcionou-se para o aumento da produção agropecuária, diversificação de atividades e agregação de valor aos cooperados. Segundo Barreiros, Protil, Duclós e Moreira (2016), a agroindustrialização tem sido a principal estratégia das cooperativas paranaenses para a agregação de valor à produção primária, gerando valor e maior grau de fidelização dos cooperados. Isso implica, necessariamente, investimento na ampliação das estruturas físicas; aumento no nível de agregação de valor aos produto; maior necessidade de recursos para o financiamento de suas atividades e aumento da utilização de recursos de terceiros. O reflexo dessa estratégia se manifestou na estrutura de capital adotada. Assim, caracterizar essa estrutura e analisar suas peculiaridades regionais torna-se o foco principal deste estudo, que pode ser sintetizado na seguinte pergunta de pesquisa: a localização regional e suas peculiaridades podem explicar os indicadores de estrutura de capital das cooperativas agropecuárias do estado do Paraná?

\section{Necessidade de capital}

Obter uma adequada estrutura de capital é um corrente desafio para a gestão financeira das cooperativas agropecuárias e, atualmente, condição necessária para a sua sustentabilidade. Seja para expandir suas atividades com novos investimentos e ou manter sua fatia de mercado e gestão do capital de giro, as cooperativas precisam de recursos, sejam próprios ou de terceiros. 
Bialoskorski Neto (2002) enfatiza que "as organizações cooperativas, para cumprir com as exigências de mercado, também estão passando por algumas importantes transformações que visam à obtenção de maior grau de eficiência econômica e de posicionamento".

Para Assaf Neto (2002), o equilíbrio financeiro de uma empresa precisa estar constituído em um fundamento básico, o capital de giro. Por isso, são necessários modelos eficientes de avaliação da situação financeira de uma empresa, pois o comportamento do capital de giro é extremamente dinâmico. Bialoskorski Neto (2012), porém, ressalta que as cooperativas apresentam certas particularidades em sua estrutura de capital que as diferem das outras empresas, pois a arquitetura organizacional influencia diretamente os custos de governança financeira. E também por serem empresas autogestionárias, capitalizadas por aportes dos cooperados e sem o objetivo de lucro, o capital de terceiros é necessário desde o início do processo de crescimento da empresa. Além disso, as cooperativas precisam, muitas vezes, financiar as operações do cooperado para garantir a aquisição de determinada quantidade de produtos e/ou venda de insumos. As particularidades da organização cooperativa, relacionadas aos seus objetivos e missão, definem algumas diferenças na avaliação de seu desempenho econômico-financeiro quando comparadas a outros tipos de organização orientadas a capital. Segundo Yang e Chaddad (2014), o desempenho das cooperativas é melhor explicado por fatores ligados a sua capacidade de gerar benefícios e satisfação aos seus membros do que por indicadores financeiros tradicionais, como ROE (retorno sobre patrimônio) e ROA (retorno sobre ativos).

As cooperativas na década de 1990 enfrentaram grandes dificuldades devido à abertura comercial e à acirrada competição com os produtos importados, que trouxeram problemas para a garantia das matérias-primas necessárias à manutenção de suas operações. Assim, a concorrência tornou-se mais acirrada também na seleção e fidelização dos produtores rurais (GIMENES e GIMENES, 2008). Costa e Bialoskorski Neto (2006) discutem o quadro de instabilidade de renda na agricultura na década de 1990 e a necessidade de adoção de estratégias de alavancagem financeira pelas cooperativas agropecuárias com foco na captação de recursos junto a entidades bancárias e fornecedores. Além disso, algumas cooperativas agropecuárias passaram a realizar operações de crédito com os asso- ciados, assumindo riscos crescentes com as instituições financeiras, principalmente em momentos de crise nas safras. Esse cenário resultou em aumento expressivo do endividamento das cooperativas e elevado ativo imobilizado com baixa rentabilidade, ou seja, as cooperativas conviveram com recursos próprios escassos, elevadas taxas de juros para financiamento e tornaram-se altamente endividadas. Para tentar auxiliar e restaurar o desenvolvimento das cooperativas, no final da década de 1990 foi lançado um programa de alongamento de dívidas, o Programa para Revitalização das Cooperativas (Recoop), no qual "as cooperativas iniciaram uma nova fase de desenvolvimento com uma considerável melhora na tesouraria, ou seja, a diferença entre o capital de giro e a necessidade de capital de giro diminuiu substancialmente" (MARTINS et al., 2014).

\section{Características regionais das cooperativas do Paraná}

Ao avaliar mais especificamente o caso do Paraná, atualmente há diversas cooperativas que se destacam no contexto econômico regional. Segundo Ocepar (2010), o dinamismo da agricultura paranaense pode ser atribuído à estratégia de colonização no Estado, que se desenvolveu com base em relações de trabalho e confiança, pois as comunidades europeias que aqui se instalaram estavam em busca do desenvolvimento pessoal. E reforça: "No contexto paranaense, o cooperativismo se destaca como instrumento de ascensão social dos cooperados e também de promoção e desenvolvimento regional baseado em cadeias agroindustriais de grande competitividade".

Segundo Kaick (2004), imigrantes europeus e japoneses, além de migrantes de outros estados, criaram diversas experiências cooperativas no Paraná. A consolidação desse modelo emergiu com os projetos de desenvolvimento cooperativo, impulsionados pelo governo federal, com o intuito de modernizar a agricultura e organizar os produtores rurais e a produção por meio de cooperativas. Com o apoio de diversas esferas governamentais, o projeto piloto surgiu nas regiões oeste e sudoeste do Paraná, com o objetivo de fortalecer e viabilizar as cooperativas da região, desenvolver novas cooperativas em áreas diferentes, delimitar a área de cada cooperativa abrangendo todos os municípios da região, incorporar cooperativas inviáveis, 
criar centrais de cooperativas para facilitar a integração vertical, dentre outros. Com o sucesso desse projeto, a experiência foi estendida para as regiões norte e noroeste e depois para o centro-sul. Assim, é possível verificar que o cooperativismo paranaense contou com o apoio de projetos regionais que levavam em consideração as peculiaridades de cada local.

Segundo Ricken (2009), os agricultores europeus trouxeram consigo o modelo de cooperativas agropecuárias que praticavam em seus países de origem, fator fundamental para organizar as estruturas de compra e venda em comum dos bens de produção e consumo, de eletrificação rural e de crédito. Além disso, foram definidos planejamentos regionais implementados a partir de 1971 que permitiram a criação de um modelo exclusivo de desenvolvimento regional do cooperativismo. Foram criados três projetos de desenvolvimento: em 1971, o Projeto Iguaçu de Cooperativismo (PIC), que abrangia as regiões oeste e sudoeste do estado do Paraná; em 1974, o Projeto Norte de Cooperativismo (Norcoop), abrangendo as regiões norte e nordeste e, em 1976, o Projeto Sul de Cooperativismo (Sulcoop), abrangendo a região centro-sul do estado. Ricken (2009) reforça que a consolidação das organizações cooperativas está ligada aos fluxos migratórios e às experiências dos imigrantes aplicadas aqui. Destes projetos localizados, foram originadas as regiões que dividem o estado do Paraná, conforme referência utilizada pela Ocepar, sendo elas: regiões centro-sul; noroeste; norte; oeste e sudoeste.

\section{Aspectos metodológicos}

Este estudo caracteriza-se como uma pesquisa aplicada quanto à sua natureza; descritiva/explicativa quanto ao seu objetivo e de modelagem matemática/estatística sobre uma base de dados já divulgada quanto à estratégia de abordagem do problema. Os dados foram obtidos por meio de uma amostra não probabilística extraída do sistema de acompanhamento da autogestão das cooperativas paranaenses vinculada à Ocepar. De 77 cooperativas, foram selecionadas as 43 cooperativas agropecuárias do estado, distribuídas por região, que apresentaram maior faturamento em 2013, conforme apresentado na Tabela 1.

Para a análise da estrutura de capital dessas regiões, os indicadores utilizados nessa pesquisa foram: a) capital de giro (CDG), que representa a diferença entre as fontes de recursos próprios e de longo prazo contra as aplicações de recursos; b) a necessidade de capital de giro (NCDG), que representa a diferença entre o ativo circulante ligado à atividade operacional contra o passivo circulante ligado à atividade operacional e c) tesouraria, que representa a diferença entre o capital de giro e a necessidade de capital de giro. Para o acompanhamento do desempenho econômico financeiro das cooperativas paranaenses esses indicadores foram adaptados, conforme modelo apresentado por Lauermann, Souza, Moreira e Souza (2016). As informações financeiras do capital de giro, necessidade de capital de giro e da tesouraria são divididos pelo total dos ativos e multiplicados por 100, conforme fórmulas apresentadas no Quadro 1, com o objetivo de transformar os dados em índice para melhor comparabilidade.

Para compor a amostra de cooperativas para este estudo, inicialmente foram obtidos dados gerais do cooperativismo agropecuário do estado do Paraná. Foram realizadas as estatísticas descritivas e analisados mais especificamente os indicadores de estrutura de capital já citados, com base nos resultados de 2013, compreendendo as cooperativas que tiveram receitas totais de mais de $\mathrm{R} \$ 30$ milhões em 2013. Juntas, essas cooperativas representam $99,5 \%$ do faturamento total do ramo no Paraná.

Tabela 1. Cooperativas da amostra por região do estado do Paraná

\begin{tabular}{lcc}
\hline \multirow{2}{*}{ Região } & \multicolumn{2}{c}{ Frequência } \\
\cline { 2 - 3 } & Absoluta & Relativa \\
\hline Centro-sul & 11 & $25,6 \%$ \\
Noroeste & 11 & $25,6 \%$ \\
Norte & 5 & $11,6 \%$ \\
Oeste & 10 & $23,3 \%$ \\
Sudoeste & 6 & $14,0 \%$ \\
Total & 43 & $100 \%$ \\
\hline
\end{tabular}

Fonte: Dados da pesquisa. 
Quadro 1. Fórmulas dos indicadores de desempenho econômico-financeiro

\begin{tabular}{|l|l|}
\hline \multicolumn{1}{|c|}{ Indicador } & \multicolumn{1}{c|}{ Fórmula } \\
\hline CDG & {$[((\mathrm{PL}+\mathrm{PNC})-\mathrm{ANC}) \div \mathrm{AT}] \times 100$} \\
\hline NCDG & {$[(\mathrm{AO}-\mathrm{PO}) \div \mathrm{AT}] \times 100$} \\
\hline T & $\mathrm{CDG}-\mathrm{NCDG}$ \\
\hline Onde: & Capital de Giro \\
CDG & Necessidade de Capital de Giro \\
NCDG & Tesouraria \\
T & Patrimônio Líquido \\
PL & Passivo não circulante \\
PNC & Ativo não circulante \\
ANC & Ativo Total \\
AT & Ativo Operacional \\
AO & Passivo Operacional \\
PO &
\end{tabular}

Fonte: Lauermann, Souza, Moreira e Souza (2016).

Os dados foram analisados por meio de técnicas de análise descritiva, análise de variância - ANOVA e mapeamento perceptual. Para isso foram utilizados o software Excel e o XLSTAT Pro, que é um software suplementar ao Excel. Para verificar a distribuição dos dados, foi realizado o teste de normalidade de Shapiro-Wilk para identificar se os dados dos principais indicadores avaliados seguem uma distribuição normal, com a apresentação do gráfico de probabilidade normal. Na análise de variância ANOVA, o objetivo foi verificar a hipótese de igualdade entre as médias regionais relacionadas ao indicador de tesouraria percentual, ou seja, se há diferença significativa considerando o indicador de tesouraria por região.

Por fim, foi realizado o mapeamento perceptual, também conhecido como escalonamento multidimensional que, segundo Hair et al. (2009), é um procedimento exploratório que determina a imagem relativa de um conjunto de objetos. Por meio da comparação desses objetos, estima sua posição relativa em espaço multidimensional, identificados por atributos específicos que correspondem a essas dimensões. Esta técnica é adequada para dois objetivos: (i) como técnica exploratória, para identificar dimensões não reconhecidas que afetam o comportamento; (ii) como um meio para obter avaliações comparativas de objetos quando as bases específicas de comparação são desconhecidas ou indefinidas. Segundo os autores, é possível comparar o mapeamento perceptual com outras técnicas de avaliação de interdependência nos seguintes quesitos: (i) análise fatorial: define estrutura reunindo variáveis em variáveis estatísticas que representam dimensões inerentes no conjunto original de variáveis. Variáveis fortemente correlacionadas se agrupam; (ii) análise de agrupamentos: define estrutura reunindo objetos de acordo com seus perfis em um conjunto de variáveis no qual objetos muito próximos entre si são colocados juntos.

Assim, a partir dos dados obtidos, é criado um mapa perceptual que representa o padrão geral de similaridades entre os resultados. Com isso, foi possível demonstrar de forma gráfica a posição das cooperativas da amostra por similaridade de indicadores, destacando quais as regióes que elas pertencem. Para elaborar o mapa, os índices foram padronizados em cinco níveis, representando o número $( \pm 1$ a \pm 5$)$ de desvios padrão que se afastam de suas médias amostrais. Nos indicadores Tesouraria e Capital de Giro (CDG), o nível 1 representa o melhor resultado e o nível 5, o pior resultado. $\mathrm{Na}$ análise da Necessidade de Capital de Giro (NCDG), o nível 1 representa a maior necessidade e o 5 , a menor necessidade.

\section{Apresentação dos resultados e discussão}

Uma característica da amostra é a dispersão dos dados, isto é, a diferença de valor de faturamento total entre as 43 empresas pesquisadas. $\mathrm{O}$ faturamento da empresa posicionada em primeiro lugar é quase o dobro da segunda classificada (Figura 1). Também se verifica que as 10 cooperativas com faturamento mais alto respondem por cerca de $3 / 4$ do faturamento total da amostra (Figura 2). 
Figura 1. Faturamento das cooperativas da amostra

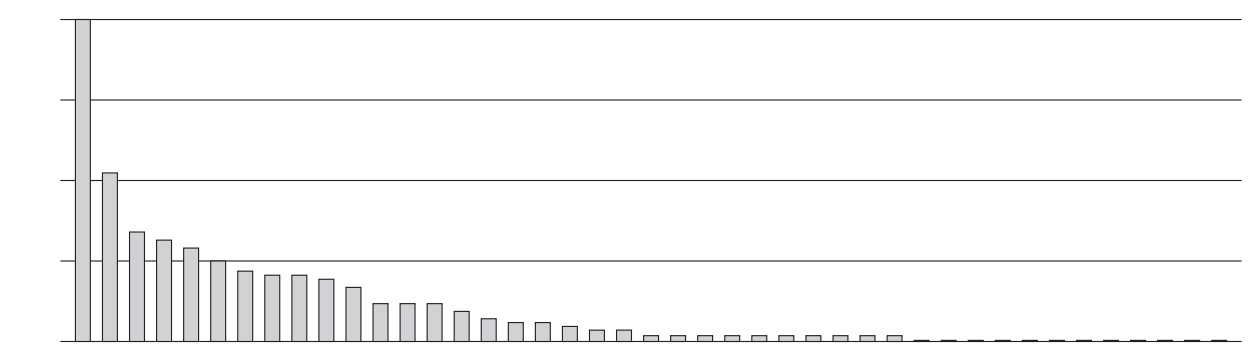

Fonte: Dados da pesquisa.

Figura 2. Faturamento acumulado das cooperativas da amostra

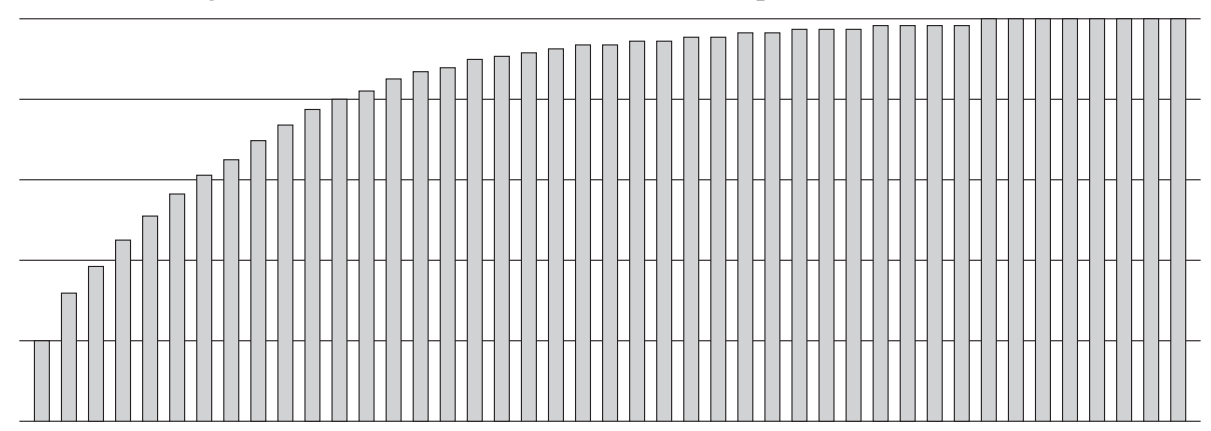

Fonte: Dados da pesquisa.

Ao serem analisados os dados de faturamento por região, conforme a Tabela 2, é possível verificar algumas peculiaridades do oeste: é a região que apresenta maior faturamento total com menor dispersão em relação ao faturamento médio (menor coeficiente de variação) e, das 10 cooperativas que representam a região, seis delas apresentaram faturamento maior que $\mathrm{R} \$ 1.000 .000 .000$.

Tabela 2. Faturamento total das cooperativas da amostra por região do estado do Paraná

\begin{tabular}{|c|c|c|c|c|c|}
\hline & I. Centro Sul & II. Noroeste & III. Norte & IV. Oeste & V. Sudoeste \\
\hline \multirow{11}{*}{ Cooperativas } & 2.317.079.277 & 7.923 .853 .022 & 1.740 .206 .351 & 4.179.136.807 & 948.259 .508 \\
\hline & 1.686 .110 .762 & 2.547.545.489 & 482.324 .229 & 2.729 .388 .876 & 276.669.092 \\
\hline & 1.403 .618 .967 & 963.221 .919 & 224.535 .515 & 2.043 .038 .661 & 164.012 .550 \\
\hline & 763.093 .991 & 551.954 .369 & 67.022 .263 & 1.643 .082 .838 & 144.585 .753 \\
\hline & 439.983 .181 & 411.036 .871 & 62.548 .989 & 1.566 .399 .687 & 114.621 .383 \\
\hline & 173.007.516 & 283.673 .453 & & 1.006 .924 .320 & 105.695 .370 \\
\hline & 85.964 .835 & 204.932.795 & & 209.478.372 & \\
\hline & 62.075 .553 & 147.069 .045 & & 181.749 .080 & \\
\hline & 38.898 .704 & 144.581 .336 & & 169.691.127 & \\
\hline & 36.992 .333 & 67.345 .810 & & 84.103 .838 & \\
\hline & 35.034 .246 & 42.319 .715 & & & \\
\hline Total & 7.041 .859 .364 & 13.287.533.821 & 2.576.637.347 & 13.812.993.605 & 1.753 .843 .656 \\
\hline Média & 640.169 .033 & 1.207.957.620 & 515.327 .469 & 1.381.299.361 & 292.307 .276 \\
\hline Desvio padrão & 805.926 .379 & 2.340 .926 .867 & 705.684 .660 & 1.345 .316 .322 & 327.168 .259 \\
\hline Coef. variação & $126 \%$ & $194 \%$ & $137 \%$ & $97 \%$ & $112 \%$ \\
\hline
\end{tabular}

Fonte: Dados da pesquisa. 
A Tabela 3 apresenta a análise das estatísticas descritivas das variáveis: totais de ingressos, número de cooperados, número de funcionários, indicador de capital de giro percentual (CDG), indicador de necessidade de capital de giro percentual (NCDG) e indicador de tesouraria percentual (T).

Na variável Ingressos Totais, que representa toda a movimentação financeira da cooperativa, ou seja, o faturamento líquido das devoluções, verifica-se um total de R\$ 38,47 bilhões com alto Coeficiente de Variação, demonstrando grande variação dos dados. As características das medidas (tendência central e dispersão) apontam uma distribuição assimétrica à direita, implicando grande número de cooperativas com valores abaixo da média, conforme já mostrado na Figura 1. A mediana revela que 50\% das cooperativas da amostra apresentam ingressos totais inferiores a R\$ 224.535.515.

O mesmo cenário é identificado nas outras variáveis: número de cooperados e número de funcionários. O total de cooperados da amostra, 131.431, corresponde a $97,2 \%$ do total do ramo no estado, também com alto Coeficiente de Variação. O total de funcioná- rios, 60.850 , representa $99,6 \%$ do total do ramo. O capital de giro (CDG) também apresenta alto Coeficiente de Variação, a despeito da proximidade entre a média e a mediana. O capital de giro (CDG) também apresenta alto Coeficiente de Variação, a despeito da proximidade entre a média e a mediana. Para a necessidade de capital de giro (NCDG), a média foi de $22,9 \%$ e a mediana, de $22,5 \%$, resultado maior que o CDG, gerando, assim, uma tesouraria ( $\mathrm{T}$ ) negativa, que é comprovada com média de $-10,5 \%$ e mediana de $-12,1 \%$, demonstrando que há maior necessidade de capital de giro que, por consequência, reflete em tesouraria negativa, ou seja, há dependência de recursos de terceiros para operacionalização das atividades.

Para realização das análises estatísticas, foi feito o teste de normalidade Shapiro-Wilk, resultando nos dados apresentados na Tabela 4. Os valores de significância resultaram todos acima de 1\%, indicando que os dados da amostra não diferem significativamente de uma distribuição normal. Na Figura 3, q-q plot, é possível visualizar com maior clareza a distribuição dos dados desses indicadores, comprovando a normalidade nos indicadores.

Tabela 3. Estatística descritiva das variáveis da amostra

\begin{tabular}{lcccccc}
\hline & Ingressos totais & Cooperados & Funcionários & CDG & NCDG & Tesouraria \\
\hline Média & 894.717 .856 & 3.057 & 1.415 & $12,4 \%$ & $22,9 \%$ & $-10,5 \%$ \\
Mediana & 224.535 .515 & 870 & 553 & $11,9 \%$ & $22,5 \%$ & $-12,1 \%$ \\
Mínimo & 35.034 .246 & 3 & 23 & $-12,7 \%$ & $-9,0 \%$ & $-45,4 \%$ \\
Máximo & 7.923 .853 .022 & 26.276 & 7.790 & $40,7 \%$ & $68,9 \%$ & $18,2 \%$ \\
Desvio padrão & $1.440 .629,416$ & 4.929 & 2.071 & $13,0 \%$ & $14,0 \%$ & $16,0 \%$ \\
Coef. variação & $161,01 \%$ & $161,23 \%$ & $146,36 \%$ & $104,83 \%$ & $61,13 \%$ & $152,38 \%$ \\
Total & 38.472 .867 .794 & 131.431 & 60.850 & & & \\
\hline
\end{tabular}

Fonte: Dados da pesquisa.

Tabela 4. Teste de normalidade dos indicadores

\begin{tabular}{ccc}
\hline Indicador & W & Significância \\
\hline Tesouraria & 0,972 & 0,358 \\
CDG & 0,976 & 0,502 \\
NCDG & 0,937 & 0,020 \\
\hline
\end{tabular}

Fonte: Dados da pesquisa. 
Figura 3. Gráfico q-q do teste de normalidade do indicadores

Q-Q plot (Tesouraria (\%))

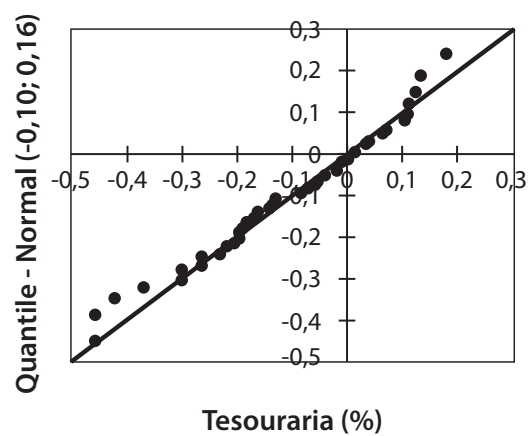

Q-Q plot (CDG (\%))

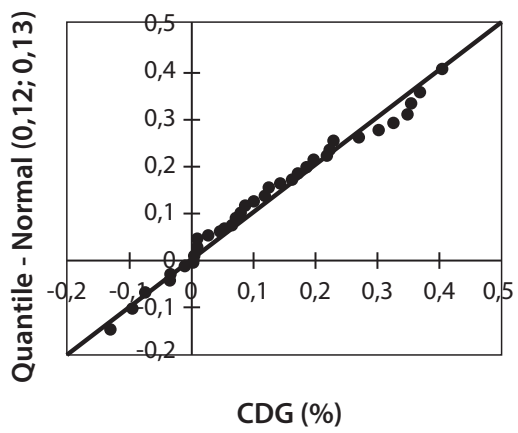

Q-Q plot (NCDG (\%))

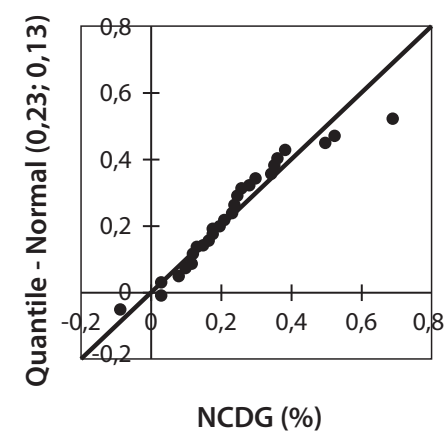

Fonte: Dados da pesquisa.

Após a avaliação da distribuição dos dados, foi verificada a existência de diferenças significativas no indicador de tesouraria entre as regiões. Para isso, foi utilizado o teste Anova e, conforme a Tabela 5 demonstra, existe evidência estatística de diferença significativa entre os resultados em pelo menos uma das cinco regiões avaliadas. $\mathrm{O}$ valor-p foi de 0,001 , levando à rejeição da hipótese nula de igualdade entre as médias do indicador de tesouraria.

No resumo dos dados foi possível verificar, pela média das regiões, algumas características distintas. Um dos destaques foi com relação à única região com tesouraria positiva, a centro-sul, demonstrando que essa região do Paraná é composta por cooperativas mais capitalizadas, com estrutura de capital adequada para suas necessidades. As cooperativas das outras regiões apresentam média de tesouraria negativa, demons- trando deficiência na estrutura de capital, ou seja, maior dependência do capital de terceiros. A região que apresentou menor tesouraria, em média, foi a oeste, o que pode ser explicado pelo alto grau de investimentos industriais das cooperativas da região, aumentando significativamente a necessidade de recursos de terceiros nas suas composições patrimoniais.

Para consolidar a análise das diferenças regionais no quesito estrutura de capital, foi realizada a análise gráfica por mapeamento perceptual, ou escalonamento multidimensional, em que os dados são avaliados por similaridade. Foram utilizados os indicadores de estrutura de capital CDG, NCDG e T. Os dados são apresentados nos eixos do gráfico para melhor visualização dos resultados. Na Figura 4 as 43 cooperativas que fazem parte da amostra são observadas, nominadas por suas respectivas regiões e agrupa-

Tabela 5. Teste Anova dos indicadores de tesouraria por região

\begin{tabular}{|c|c|c|c|c|c|c|}
\hline \multicolumn{7}{|c|}{ Anova: fator único / Resumo } \\
\hline Grupo & Contagem & & Soma & Média & & Variância \\
\hline Centro-Sul & 11 & & $48,29 \%$ & $4,39 \%$ & & 0,014 \\
\hline Noroeste & 11 & & $-153,43 \%$ & $-13,95 \%$ & & 0,029 \\
\hline Norte & 5 & & $-55,23 \%$ & $-11,05 \%$ & & 0,010 \\
\hline Oeste & 10 & & $-233,72 \%$ & $-23,37 \%$ & & 0,016 \\
\hline Sudoeste & 6 & & $-57,13 \%$ & $-9,52 \%$ & & 0,016 \\
\hline \multicolumn{7}{|c|}{ Anova } \\
\hline Fonte da variação & SQ & gl & MQ & $\mathbf{F}$ & valor-P & F crítico \\
\hline Entre grupos & 0,4234 & 4 & 0,105843451 & 5,7 & 0,0011 & 2,6190 \\
\hline Dentro dos grupos & 0,7056 & 38 & 0,018569545 & & & \\
\hline Total & 1,1290 & 42 & & & & \\
\hline
\end{tabular}

Fonte: Dados da pesquisa. 
Figura 4. Mapa perceptual

\section{Asymmetric variable plot}

(axes F1 and F2: 68,29\%)

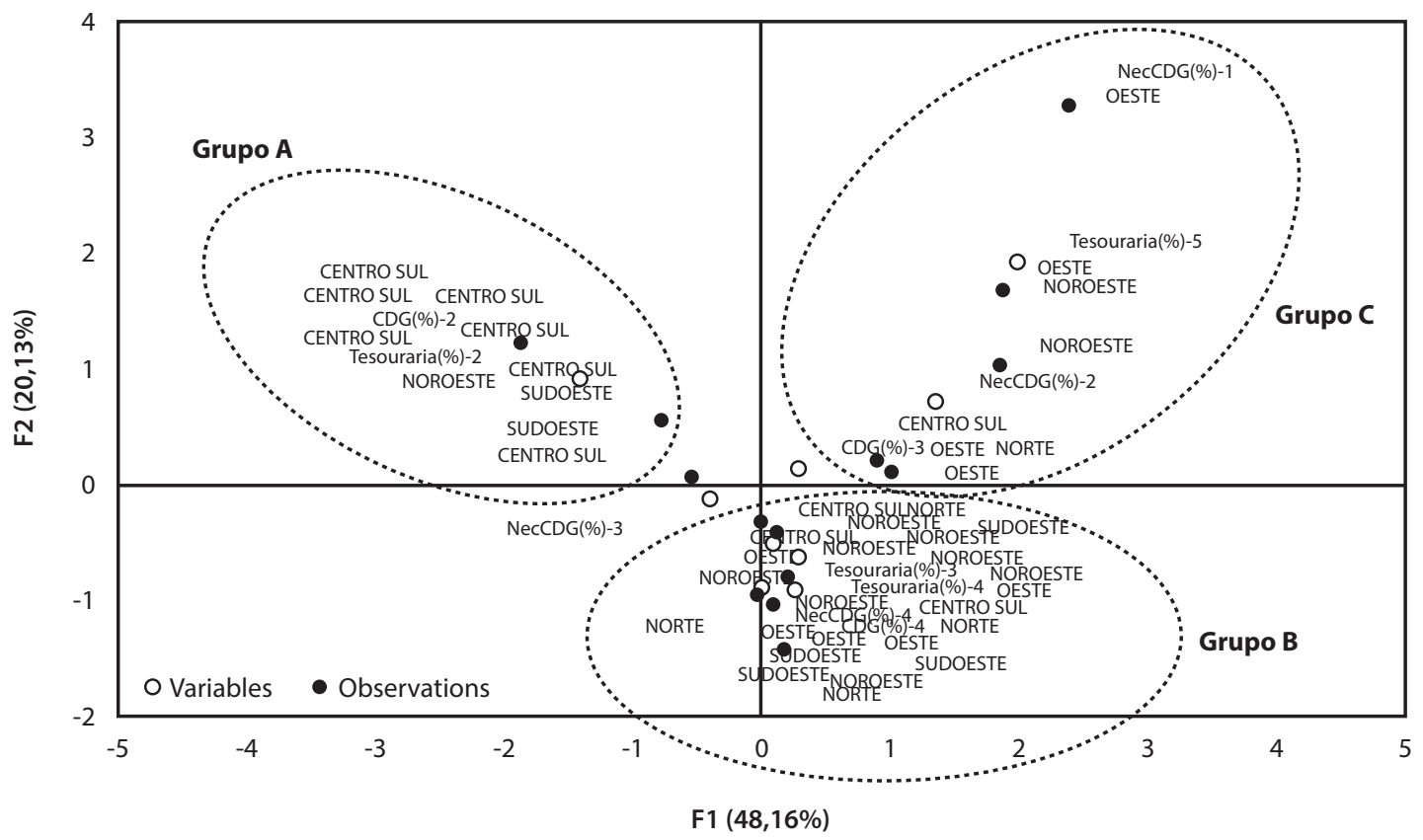

Fonte: Dados da pesquisa.

das por similaridades. É possível identificar três grupos distintos (A, B e C) na análise: o grupo A, composto por cooperativas com maior nível de capital de giro e menor necessidade de capital de giro, ou seja, são as que apresentam tesouraria positiva, estrutura de capital adequada para suas necessidades; o grupo B, representado por cooperativas com tesouraria negativa, com baixos índices de capital de giro e com níveis de tesouraria mais próximos da média e o grupo $\mathrm{C}$, representado pelas cooperativas com menor tesouraria, reflexo da maior necessidade de capital de giro.
Verifica-se que a maior parte das cooperativas está no grupo B, que é composto por cooperativas de todas as regiões. Isso demonstra que a maior parte das cooperativas é deficitária em relação a sua estrutura de capital, precisando necessariamente de recursos de terceiros para compor seu capital de giro. Essas cooperativas apresentam NCDG de nível médio, porém, com baixo nível de $C D G$, refletindo tesouraria negativa.

A Tabela 6 apresenta o número de cooperativas enquadradas em cada grupo por região. É possível confirmar que a maior parte das cooperativas está

Tabela 6. Distribuição das cooperativas por grupo e região

\begin{tabular}{lcccc}
\hline \multirow{2}{*}{ Região } & \multicolumn{3}{c}{ Grupos } & \multirow{2}{*}{ Total } \\
\cline { 2 - 4 } & $A$ & $B$ & $C$ & 11 \\
\hline Centro-Sul & 7 & 3 & 1 & 11 \\
Noroeste & 1 & 8 & 2 & 5 \\
Norte & 0 & 4 & 1 & 10 \\
Oeste & 0 & 6 & 4 & 6 \\
Sudoeste & 2 & 4 & 0 & 43 \\
Total & 10 & 25 & 8 & \\
\hline
\end{tabular}

Fonte: Dados da pesquisa. 
enquadrada no grupo B, composto por 25 cooperativas que, na maior parte, localizam-se nas regiões noroeste e oeste. Os grupos A e C representam os extremos da análise. O grupo A é formado por 10 cooperativas, que são as mais capitalizadas, sendo que $70 \%$ delas estão situadas na região centro-sul. O grupo C é formado por oito cooperativas, sendo que a maior parte destas está situada na região oeste (50\%), onde estão enquadradas as cooperativas com menor nível de capitalização devido ao alto nível de NCDG, ou seja, maior necessidade de recursos de terceiros para composição do fluxo de caixa.

Avaliando os resultados por regiões, verifica-se que, na região centro-sul, composta por 11 cooperativas, sete delas estão enquadradas no grupo A, ou seja, a característica principal da região é ser composta por cooperativas com tesouraria positiva, que estão capitalizadas. A maior parte dessas cooperativas é formada por cooperados de colônias de origem europeia, principalmente holandeses e alemães. A região tem menor nível de industrialização se comparada à região oeste, por exemplo. O Quadro 2 apresenta um resumo das características da estrutura de capital por grupos e relaciona as características dos fluxos migratórios.

O Quadro 3 apresenta o faturamento das cooperativas da amostra por região, indicando em quais delas a tesouraria é positiva e negativa e quais são as etnias/ fluxos migratórios predominantes. A região noroeste, composta por 11 cooperativas, tem a maior parte de suas cooperativas no grupo $B$, apenas uma cooperativa no grupo A e duas no grupo $\mathrm{C}$, demonstrando que a maior parte das cooperativas da região possui tesouraria negativa devido ao baixo grau de capital de giro, mas com tesouraria mais próxima da média. A mesma análise é válida para a região norte que, com cinco cooperativas, quatro se enquadram no grupo B.

Quadro 2. Avaliação da estrutura de capital por fluxo migratório

\begin{tabular}{|c|c|c|c|c|c|}
\hline Grupos & CG & NCG & Tesouraria & Estrutura de capital & Fluxos migratórios \\
\hline A & $\uparrow$ & $\downarrow$ & $>0$ & Adequada & c \\
\hline B & $\downarrow$ & $\uparrow$ & $<0$ & Não adequada & a \\
\hline C & $\downarrow$ & $\uparrow$ & $<0$ & Não adequada & . \\
\hline
\end{tabular}

Legenda dos fluxos migratórios:

A. Regiões oeste e sudoeste - influenciadas pelo Projeto PIC - Cooperativas com origem da migração do Sul do País (RS e SC), principalmente Rio Grande do Sul;

B. Regiões norte e noroeste - influenciadas pelo Projeto Norcoop - Cooperativas com origem da migração de São Paulo e de etnia japonesa;

C. Região centro-sul - influenciadas pelo Projeto Sulcoop - Cooperativas com origem na imigração europeia, principalmente alemães e holandeses.

Fonte: Dados da pesquisa.

Quadro 3. Faturamento e situação da tesouraria por região, por grupo e etnias/fluxos migratórios predominantes

\begin{tabular}{|c|c|c|c|c|c|}
\hline & I. Centro-Sul & II. Noroeste & III. Norte & IV. Oeste & V. Sudoeste \\
\hline \multirow{12}{*}{ 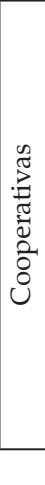 } & 2.317.079.277 & 7.923.853.022 & 1.740 .206 .351 & 4.179 .136 .807 & 948.259 .508 \\
\hline & 1.686 .110 .762 & 2.547 .545 .489 & 482.324 .229 & 2.729 .388 .876 & 276.669 .092 \\
\hline & 1.403 .618 .967 & 963.221 .919 & 224.535 .515 & 2.043 .038 .661 & 164.012 .550 \\
\hline & 763.093 .991 & 551.954 .369 & 67.022 .263 & 1.643 .082 .838 & 144.585 .753 \\
\hline & 439.983.181 & 411.036 .871 & 62.548 .989 & 1.566 .399 .687 & 114.621 .383 \\
\hline & 173.007 .516 & 283.673 .453 & & 1.006 .924 .320 & 105.695 .370 \\
\hline & 85.964 .835 & 204.932 .795 & & 209.478 .372 & \\
\hline & 62.075 .553 & 147.069 .045 & & 181.749 .080 & \\
\hline & 38.898 .704 & 144.581 .336 & & 169.691 .127 & \\
\hline & 36.992 .333 & 67.345 .810 & & 84.103 .838 & \\
\hline & 35.034 .246 & 42.319 .715 & & & \\
\hline & c; & $\mathrm{b}$ & $\mathrm{b}$; & $\mathrm{a} ;$ & $\mathrm{a} ;$ \\
\hline
\end{tabular}

Notas: Valores em Negrito = tesouraria positiva; Itálico = tesouraria negativa.

Legenda: Etnias predominantes/Fluxos migratórios:

a. Regiões oeste e sudoeste - Cooperativas com origem da migração do Sul do País (RS e SC), principalmente Rio Grande do Sul;

b. Regiões norte e noroeste - Cooperativas com origem da migração de São Paulo e de etnia japonesa;

c. Região centro-sul - Cooperativas com origem na imigração europeia, principalmente alemães e holandeses.

Fonte: Dados da pesquisa. 
Na região oeste, com 10 cooperativas na análise, $60 \%$ delas estão no grupo B, $40 \%$ estão no grupo C e nenhuma está no grupo A, tendo como característica principal cooperativas com tesouraria negativa, algumas por um nível baixo de capital de giro e outras por elevada necessidade de capital de giro. Salienta-se que uma das principais características da região é a industrialização, que tem por consequência maior necessidade de investimentos. Estes são realizados, na maior parte, com recursos de terceiros, levando a esse resultado na estrutura de capital. A região sudoeste tem seis cooperativas, com quatro delas enquadradas no grupo B e 2 no grupo A.

Enfim, pode ser verificado que o principal destaque relacionado à estrutura de capital em cooperativas está na região centro-sul, que poderia servir como tema de estudo e aprofundamento do modelo utilizado pelas principais cooperativas da região em termos de capitalização e a participação do cooperado no processo. Também foi possível destacar que a maior parte das cooperativas do estado utiliza recursos de terceiros para compor seu capital de giro, ou seja, por ter tesouraria negativa, demonstram necessidade de maior capitalização para o desenvolvimento de parte das suas atividades e encontram nas instituições financeiras grandes parcerias para a realização de investimentos. Mesmo com políticas de capitalização, com o aumento das reservas patrimoniais ou geração de sobras, a velocidade do crescimento do patrimônio líquido é menor do que dos investimentos e/ou da necessidade gerada devido ao crescimento expressivo destas organizações.

\section{Conclusão}

Com o objetivo de demonstrar a estrutura de capital das cooperativas do ramo agropecuário do estado do Paraná e analisar suas peculiaridades regionais, este estudo comprovou que há diferenças significativas nessa relação. Por meio da utilização de métodos estatísticos foi possível verificar que a região sul se distingue das demais no quesito estrutura de capital. Das 11 cooperativas representativas dessa região, sete delas apresentaram tesouraria positiva devido ao capital de giro existente ser maior que a sua necessidade. A tesouraria positiva, em geral, implica mais segurança para os cooperados nas operações da cooperativa; mais poder de barganha em negociações comerciais, por meio de adiantamentos de compras, descontos etc. e possibilidade de investimentos com recursos próprios, reduzindo, assim, as despesas financeiras. É evidente que essas situações também podem ocorrer nas outras cooperativas enquadradas nos grupos B e C, porém, as possibilidades ficam mais limitadas na medida em que a tesouraria negativa fica maior.

Outra característica relevante verificada na análise é que as cooperativas da região oeste, por serem mais industrializadas, têm maior necessidade de capital de giro, ou seja, seus investimentos em diversificação e verticalização acabam comprometendo seu capital de giro e exigindo maior necessidade de capital de terceiros (instituições financeiras) para esses investimentos. Porém, apesar de aumentar o risco, podem gerar maior retorno aos cooperados por meio da agregação de valor na produção dos mesmos. Esse fato já vem alterando algumas características da região centro-sul, que nessa busca está investindo mais em industrialização. Mas esse movimento está sendo condicionado à maior participação dos cooperados nos investimentos, para não comprometer sua estrutura de capital formada ao longo de diversos anos.

Enfim, esta pesquisa buscou contribuir com a discussão da estrutura de capital de cooperativas agropecuárias e verificou que existe relação significativa entre a região geográfica das cooperativas no Paraná e seus indicadores de estrutura de capital. Mas embora o estudo tenha identificado as diferentes estratégias de capitalização entre as diversas cooperativas e suas respectivas regiões, não foi intenção entender qual modelo poderia ser eleito o melhor para o setor, o que sugere estudos mais aprofundados sobre o tema. Além disso, devido à identificação de diferenças significativas de estrutura de capital nas cooperativas de acordo com as regiões do estado, considerando uma discriminação por variáveis de agrupamento relacionadas a etnias e fluxos migratórios, sugere-se como pesquisa futura a investigação da possível influência de questões culturais nos resultados e estilo de gestão das cooperativas.

\section{Referências}

ASSAF NETO, A. Estrutura e análise de balanços: um enfoque econômico-financeiro. 7. ed. São Paulo: Atlas, 2002. 
BARREIROS, R. F., PROTIL, R. M., DUCLÓS, L. C. e MOREIRA, V. R. Commitment in the process of translation and control of strategy in Brazilian agroindustrial cooperatives. Revista Brasileira de Estratégia, v. 9 , n. 3, p. 275-293, 2016.

BIALOSKORSKI NETO, S. Economia e gestão de organizações cooperativas. 2. ed. São Paulo: Atlas, 2012.

BRASIL, H. V. e BRASIL, H. G. Gestão financeira das empresas: um modelo dinâmico. 4. ed. Rio de Janeiro: Qualitymark, 1992.

COSTA, D. R. M. e BIALOSKORSKI NETO, S. Rating de cooperativas agropecuárias: uma contribuição metodológica. Revista de Economia e Agronegócio, v. 4, n. 4, p. 509-535, 2006.

GIMENES, R. M. T. e GIMENES, F. M. P. Aplicabilidade da análise dinâmica do capital de giro como instrumento de avaliação da gestão financeira em cooperativas agropecuárias. Revista Econ. Contemp., v. 12, n. 1, p. 129-150, 2008.

HAIR JR., J. F. et al. Análise multivariada de dados. 6. ed. Porto Alegre: Bookman, 2009.

ILIOPOULOS, C., COOK, M. L. e CHADDAD, F. Agricultural cooperatives in netchains. Journal on Chain and Network Science, v. 16, n. 1, p. 1-6, 2016.

KAICK, G. van. Early milestone for cooperative selfmanagement. In: Brazilian cooperativism: the conquest of autonomy. Brasilia, USAID: ACDI/VOCA, 2004, p. 23-28. Disponível em: < http://www.acdivocacoopex. org/acdivoca/CoopLib.nsf/dfafe3e324466c3785256d96
004f15a8/2ae7fd38dc94c50d8525754d005e78b8/\$FILE/ BrazilianCooperativismTheConquestofAutonomy. pdf $>$. Acesso em: 30 jul. 2014.

LAUERMANN, G. J. et al. Desempenho econômicofinanceiro de cooperativas: o caso do programa de monitoramento da autogestão das cooperativas agropecuárias do Paraná. Revista de Gestão e Organizações Cooperativas, v. 3, n. 6, p. 59-72, 2016.

MARTINS, G. et al. Agro: conjuntura e cooperativismo. Curitiba: Ocepar-Sescoop/PR, 2014.

OCEPAR. Agronegócio e o cooperativismo no Paraná. Curitiba: Ocepar: Sescoop/PR, 2010.

. Fórum Financeiro 2014. Disponível em: $<$ http://www.paranacooperativo.coop.br/ppc/index. php/sistema-ocepar/comunicacao/2011-12-07-11-06-29/ ultimas-noticias/98993-forum-financeiro-i-eventoreune-80-profissionais-de-cooperativas-e-agentesfinanceiros >. Acesso em: jun. 2014.

RICKEN, J. R. A integração econômica e social nas cooperativas agropecuárias do Paraná, 2009. 114 p. Dissertação (Mestrado Executivo em Gestão Empresarial) - Escola Brasileira de Administração Pública e de Empresas, Fundação Getulio Vargas, Rio de Janeiro, 2009.

YANG, S. e CHADDAD, F. R. The relationship between performance and governance in agricultural cooperatives: a structural equation modeling approach. International Journal of Co-operative Management, v. 7, n. 1, p. 43-57, 2014.

Todo o conteúdo deste periódico, exceto onde estiver identificado, está licenciado sob uma Licença Creative Commons (cc by 4.0) 